\title{
An Incomplete Psychological Novel: a Psychoanalytical Analysis of Hazel Lancaster in John Green's The Fault in Our Stars
}

\author{
Nathania Astria Pangestu \& F.X. Dono Sunardi \\ Faculty of Language and Arts, Universitas Ma Chung, Malang \\ dono.sunardi@machung.ac.id
}

\begin{abstract}
This paper is a psychoanalytical analysis of John Green's The Fault in Our Stars (2012), aiming at identifying Hazel Grace Lancaster's, the main character of the novel, self defense mechanisms and core issues as well as their potential causes. In so doing, this paper employs psychoanalysis theory by Sigmund Freud as its analytical tool. As a literary research, it uses a descriptive qualitative method, where we read the novel thoroughly, focused on the character and characterization of Hazel Grace and compared and analyzed it along with the theories that are used. The finding of this research is that this novel does contain its main character's self-defense mechanisms and core issues evidence. The potential cause of the self-defense mechanisms can also be inferred from the character's development and childhood. And yet, since this novel does not provide any clue or evidence as to how the main character develop her Berliore issues, we come to the conclusion that this novel is not a complete psychological novel.
\end{abstract}

Keywords: psychoanalysis, self-defense mechanisms, core issues

\section{Introduction}

As one of expressions of human beings, literature represents human life. As such, literature can be studied using psychological perspectives (Endraswara, 2011). Although many critics disagree with the use of psychoanalysis to understand the behavior of literary characters that are not real people with real psyches, some others have successfully defended this with two important reasons (Tyson, 2006).

Those two important reasons are (1) when analyzing literary characters using psychoanalysis, a researcher is not suggesting that the characters are real people but that they only represent the psychological experience of human beings in general; and (2) psychoanalysis aims at analyzing literary representations as illustrations of real-life issues such as when someone analyzes the character's behavior from the perspective of any critical theory (Tyson 2006). Because of these two reasons, psychological approach to literary work is valid.

The Fault in Our Stars (2012) is one of the bestselling novels written by John Green. It tells about a couple that suffers from cancer. The main character of this novel is a seventeen-year old teenager named Hazel Grace Lancaster. She suffers from thyroid cancer. Later on in the narration, she meets a boy named Augustus Waters who also suffers from cancer. They fall in love and enjoy some great times together, but at the end, Augustus died. This paper will explore Hazel's life and investigates it as a psychological phenomenon in human's life in the real world using psychoanalysis.

The study sets to achieve two objectives: (1) to identify the self-defense mechanisms of Hazel Grace as the main character of The Fault in Our Stars and what causes them, and 
(2) to identify the core issues of Hazel Graze and what causes them.

\section{An Overview of Psychoanalysis}

It was Sigmund Freud (1856-1939) who developed psychoanalysis. In Freudian psychoanalysis, unconscious mental activities determine conscious psychic activities. Rajeevan (2011) wrote that the term psychoanalysis itself has three distinctive meanings. First, it is defined as a school of psychology, which emphasizes the psychic determinism and dynamics and also the importance of childhood experiences in forming one's adult personality and behavior. Second, psychoanalysis is defined as a specialized method for investigating the unconscious mental activities. And lastly, psychoanalysis is defined as a therapeutic method for the investigation and treatment of mental disorders, especially the neurotic disorders.

From those three distinctive meanings, the second meaning, i.e. psychoanalysis as a specialized method for investigating the unconscious mental activities, is particularly relevant to this research. Here, what we do is analyzing and investigating the unconscious mental activities of Hazel, the main character of The Fault in Our Stars. Moreover, the first meaning of psychoanalysis above-mentioned is also important for this research. In this case, we try to relate the main character's childhood experiences with her behavior and mental activities after she grows up.

In Freudian psychoanalysis, the human mind is divided into three divisions (Rajeevan, 2011). The first division is the conscious mind, which is constituted of events, memories, fantasies and the sensations from sense organs along with the feelings and emotions of which human is aware at the moment. The second part is the pre-conscious mind that consists of the past psychic experiences and desires. And the third division is the unconscious mind which consists of those painful experiences and emotions, those wounds, fears, guilty desires, and unresolved conflicts we do not want to know about.
Out of the three levels, the unconscious mind is the most important level for the discussion of this paper. Here, we investigate fears, guilty, desires and unresolved which manifest as self-defense mechanisms and core issues of the main character of The Fault in Our Stars. According to Tyson (2006), defenses are the processes by which the contents of our unconscious are kept in the unconscious position. It means that defenses are the processes when, human keeps his anxiety unconsciously in order to avoid knowing what he feels he cannot handle.

Berger (2004) wrote that there are fourteen defenses, which include:

a. Selective perception: occurs when someone only hears and sees what he feels he can handle.

b. Selective memory: occurs when someone modifies his memories by keeping the good memories and forgetting the painful experiences or bad memories.

c. Denial or disavowal: occurs when someone does not believe some aspects of reality.

d. Avoidance: occurs when someone stays away from people or situations that are liable to make him anxious by stirring up some unconscious.

e. Displacement: occurs when someone "takes it out" on someone or something less threatening than the person who caused his fear, hurt, frustration, or anger.

f. Projection: occurs when someone ascribes the fear, problem, or guilty desire to someone else and then condemning him or her for it, in order to deny that he has it himself.

g. Regression: occurs when someone returns temporarily to a past psychological state, which is not just imagined but relived.

h. Ambivalence: occurs when someone has a simultaneous feeling of love and hate or attraction and repulsion toward the same person or object.

i. Fixation: occurs when someone has an obsessive preoccupation or attachment to something.

j. Identification: occurs when someone subscribes to a desire to become similar to someone or something in some aspect of thought, value or behavior. 
k. Rationalization: occurs when there is an offering of logical reasons or excuses for behavior generated by unconscious and irrational determinants.

1. Reaction formation: occurs when a pair of ambivalent attitudes generates problems, so one element is suppressed and kept unconscious by overemphasis on the other (its opposite), although it does not disappear.

m. Repression: refers to the barring from consciousness of ideas, feelings, thoughts, fantasies, and memories.

n. Suppression: occurs when someone purposefully puts out of his mind and consciousness something that he finds painful.

Another important term related to psychoanalysis is anxiety. Tyson (2006) stated that anxiety is the psychoanalytic terms of several disorders that cause nervousness, fear, and worrying. Anxiety occurs when our defenses momentarily break down. Anxiety is an important experience because it can reveal our core issues. Core issues are issues that define our being in fundamental ways that we carry through life (Kathy 2015). There are five common core issues:

a. Fear of intimacy: the chronic and overpowering feeling that emotional closeness will seriously hurt or destroy us and that we can remain emotionally safe only by remaining at an emotional distance from others at all times.

b. Fear of abandonment: the unshakable belief that our friends and loved ones are going to desert us (physical abandonment) or do not really care about us (emotional abandonment).

c. Fear of betrayal: the feeling that our friends and loved ones cannot be trusted, for example, cannot be trusted not to lie to us, not to laugh at us behind our backs, or in the case of romantic partners, not to cheat on us by dating others.

d. Low self-esteem: the belief that we are less worthy than other people and, therefore, do not deserve attention, love, or any other of life's rewards.

e. Insecure or unstable sense of self: the inability to sustain a feeling of personal identity, to sustain a sense of knowing ourselves.

\section{Hazel Grace Lancaster's Self-defense Mechanisms}

Hazel Grace Lancaster is the main character of John Green's The Fault in Our Stars. As a round character, whose personality develops from time to time in the novel, Hazel, too, unconsciously employs selfdefense mechanisms in order to press her anxieties so that they stay in the unconscious level. Reading through the novel, we found several defenses employed by Hazel. They are:

\section{Selective Perception}

The first self-defense mechanism found in the novel that is employed by Hazel is selective perception. As a self-defense mechanism, selective perception happens when someone only hears and sees what she feels she can handle (Berger 2004). In the novel, there are several textual evidences that support that Hazel only hears and sees as well as believes something that makes her feel better. One of such evidences that is substantial read as follows:

Also, Anna is honest about all of it in a way no one else really is. Throughout the book, she refers to herself as the side effect, which is just totally correct. Cancer kids are essentially side effects of the relentless mutation that made the diversity of life on earth possible. So as the story goes on, she gets sicker... (Green, 2013: 49)

Hazel loves very much reading a novel entitled An Imperial Affliction, in which Anna, the main character, suffers from cancer just like herself. She reads the novel everyday, back to back. From that novel, Hazel learns from Anna how to comfort herself despite her cancer. Anna says things that Hazel would love to hear, things that in reality never been told to her by people around her. Anna offers some relief that makes Hazel Grace feel comfortable when she is depressed. Anna, for example, believes that children with cancer are not those who suffer illness but they are 
merely side effects of a mutation process that eventually will make the world more beautiful with diversity.

\section{Denial}

Another self-defense mechanism employed by Hazel in the novel is denial. According to Berger (2004), denial occurs when someone believes or wants to believe that a problem does not exist or an unpleasant incident never happened. Denial, in Hazel, manifests in her constant acting that everything about her is fine, despite the realization that she is not.

I'm Hazel, I'd say when they'd get to me. Sixteen. Thyroid originally but with an impressive and long-settled satellite colony in my lungs. And I'm doing okay (Green, 2013: 5).

Hazel wants to believe, and wants others to believe, that she is just fine, even though she suffers an incurable cancer that will definitely lead her to her end. By keeping saying that she is fine, Hazel denies that she is sick and dying. She lies to herself and others. She keeps saying that she is fine even though she is not.

\section{Avoidance}

Avoidance is a self-defense mechanism that occurs when someone tries to stay away from people or situations that are liable to make him anxious by stirring up some unconscious experience or emotion (Berger 2004). In The Fault in Our Stars, Hazel decides to drop out from her school because of her illness. Considering this as not enough, she tries hard to stay away from her friends. Hazel takes these steps because she feels hurt every time she meets and talks to them. She feels jealous with her healthy and "normal" friends. Hazel also does not like the way her friends see her. They see her with pity and treat her like a sick person. As result, Hazel chooses to be alone and spends her time reading a book.

And I liked Kaitlyn, too. I really did. But three years removed from proper full-time schoolic exposure to my peers, I felt a certain unbridgeable distance between us. I think my school friends wanted to help me through my cancer, but they eventually found out that they couldn't. For one thing, there was no through. So I excused myself on the grounds of pain and fatigue, as I often had over the years when seeing Kaitlyn or any of my other friends. In truth, it always hurt. It always hurt not to breath like a normal person, incessantly reminding your lungs to be lungs, forcing yourself to accept as unsolvable the clawing scraping inside-out ache of underoxygenation. So I wasn't lying, exactly. I was just choosing among the truth (Green, 2013: 45).

It is clear from the evidence that Hazel avoids meeting people who potentially could hurt her. Her decision to choose book over people is a manifestation of that particular self-defense mechanism because according to Hazel books are not going to hurt her.

\section{Displacement}

As a self-defense mechanism, displacement works similarly to avoidance. If in avoidance someone simply tries to stay away from ones or things that hold potentials to hurt him, displacement goes a bit further. In displacement, someone does not only avoid them but also picks something or another person that is less threatening than something or the person who caused his fear, hurt, frustration, or anger (Berger 2004). In The Fault in Our Stars, Hazel somehow feels threatened by the presence of her friends and parents around her. Her choosing books over her school friends and parents does not only suggest her avoidance of them but also her assumption that books are much less threatening to her than her friends and parents. As Hazel does not see herself capable of defending herself both in front of her parents and friends, she perceives books as the least "dangerous" thing for her. She likes being alone with her books.

Anyway, I really did like being alone. I liked being alone with poor Staff Sergeant Max Mayhem (Green, 2013: 47) 
We see form the evidence that Hazel uses displacement, which is a mechanism to replace someone or something that causes fear with someone or something that is less threatening.

\section{Fixation}

Another self-defense mechanism employed by Hazel in the novel is fixation. This defense occurs when someone obsessively attaches to something (Berger 2004). The Fault in Our Stars tells how Hazel reads An Imperial Affliction every day. She has been reading the novel many times since she had been diagnosed with thyroid cancer. The reason Hazel loves An Imperial Affliction is because the novel tells stories of children with cancer. She particularly likes the main character of the novel, Anna, who suffers from blood cancer. Unlike the other children with cancer featured in the novel, Anna does not start a charity that raises money to fight cancer; Anna starts a charity to cure Cholera instead. Hazel's fixation to the novel is also caused by her amazement of how the novel ends right in the middle of a sentence. Since the novel does not have an ending, she can start to imagine what happens next.

And then I started reading An Imperial Affliction for the millionth time... I know it's a very literary decision and everything and probably part of the reason I love the book so much, but there is something to recommend a story that ends (Green, 2013: 49)

Hazel's obsession to reading the same novel repeatedly shows that she develops fixation as one of her self-defense mechanisms. It is likely that this also a result of her insecurity. Fixation happens because someone does not feel safe to try new things. That is why they stick to familiar things. That is also why Hazel keeps reading the same novel again and again.

\section{Identification}

Identification as a self-defense mechanism is a desire to become similar to someone or something in some aspects of thought, value or behavior (Berger 2004). In
The Fault in Our Stars, Hazel tries to imitate Anna from An Imperial Affliction. It is so much that Hazel identifies herself with Anna that she adopts Anna's belief of children with cancer as a side effect of the relentless mutation that will make the world beautiful in diversity. More than that, Hazel also imitates Anna's behavior, styles and value.

I spent like thirty minutes debating with Mom the various benefits and drawbacks of the available outfits before deciding to dress as much like Anna in AIA as possible: Chuck Taylors and dark jeans like she always wore, and a light blue T-shirt (Green, 2013: 178).

What we can conclude from here is that Hazel employs identification as her selfdefense mechanism unconsciously. She loves the character of Anna so much until she does not realize that she tries to imitate her in several aspects of her life, i.e. her thought, value and behavior.

\section{Rationalization}

Berger (2004) suggested that rationalization occurs when there is an offering of logical reasons or excuses for behavior generated by unconscious and irrational determinants. In The Fault in Our Stars, Hazel tries to give logical explanation for her illogical behavior and act. Hazel, for example, states that the reason she goes to Support Group, a group that help children with cancers like Hazel, and allows the nurses there to inject medicine to her is because she wants to make her parents happy. But in fact, unconsciously, she does this because, deep inside her, she still wants to be a healthy person without cancer in her lungs.

I went to Support Group for the same reason that I'd once allowed nurses with a mere eighteen months of graduate education to poison me with exotically named chemicals: I wanted to make my parents happy (Green, 2013: 7-8).

Hazel employs rationalization as one of her several self-defense mechanism to conceal the motives that would arouse anxiety or guilt in her. She always gives more 
logical and acceptable explanation to her behavior in order to keep the real reason hidden.

Now that we have found and discussed Hazel's self-defense mechanisms that she employs when she faces her anxiety and wants to keep the anxiety unconsciously in order to avoid knowing what she thinks she cannot handle (Tyson 2006), the next step is to understand their cause. In psychoanalysis, the cause of self-defense mechanisms can be traced from one's childhood experiences or several events that trigger him or her to use self-defense mechanisms. In The Fault in Our Stars, Hazel is told to have a great, happy childhood until she was twelve. Maybe it is because nothing is particularly interesting or memorable from Hazel's early childhood period. The fact is that the novel does not even mention about it. It is almost like a blind spot where the author does not inform anything to us as readers. Things, however, start to change when Hazel reaches thirteen when she is diagnosed with Stage IV thyroid cancer. Due to her knowledge that the cancer is incurable, she loses hope and feels depressed. Hazel has to undergo several surgeries and chemotherapies, drop out from her schools, stay away from her friends, and spend her time in reading novel about cancer girl.

Hazel's suffering does not stop there because her lungs start to fill up with water. This makes her hard to breathe normally for several months. The doctor says she has pneumonia that could possibly lead to her death. Her mother and father accompany her during this critical period of her life. One day, when Hazel struggles very hard to just take a breath, which makes her thinking that she will die soon, without her mother's knowing she overhears her mother tells her father how terrified it is for her that she will not be a mother anymore if Hazel dies. Hazel, who up to that point does not have any fear of death, feels very bad. She thinks if she dies she will leave her mother, make her mother sad. Probably her mother is not going to remember her anymore. She does not want to wake up to face the harsh reality but she is alive because her doctor manages to get some of the water out of her lungs. This has become
Hazel's first recorded traumatic experience. And since then, she starts to hate her life and herself because during her life, she will only make people hurt and sad. She also starts to have fear of death because she does not want other people to be sad when she dies. She starts employing several self-defense mechanisms discussed above to comfort herself and conceal her anxieties.

\section{Hazel Grace Lancaster's Core Issues}

Anxiety is one key term in psychoanalysis, because by analyzing it closely we can get some insights into someone's core issues. Luckily enough, sometimes, like when are dreaming in our sleep or when we feel very tired and about to sleep or when we are experiencing extreme feeling of being depressed, our self-defenses momentarily break down, and when it happens, we can have a glimpse of anxiety and brings it up to the level of consciousness (Tyson 2006). Core issues are more pertinent than self-defense mechanisms because they are more deeply rooted in one's history of life. Some psychoanalysis theorists believe that one's core issues are mostly defined before he or she reaches the age of twelve. As such, core issues, as the names suggest, function like a true color of one's personality. No matter what one does, or what one decides to do, it will be heavily influenced by his or her core issues. Hazel of The Fault in Our Stars has three major core issues. They are:

\section{Fear of Intimacy}

Fear of intimacy is the chronic and overpowering feeling that emotional closeness will seriously hurt or destroy us and that we can remain emotionally safe only by remaining at an emotional distance from others at all time (Tyson 2006). Hazel seems to be heavily inflicted by this fear of intimacy that she always tries to maintain a safe emotional distance to anyone around her.

I'm a grenade," I said again. "I just want to stay away from people and read books and think and be with you guys because there's nothing I can do about hurting you; you're too invested, so just please let 
me do that, okay? I'm no depressed. I don't need to get out anymore. And I can't be a regular teenager, because I'm a grenade (Green, 2013: 99).

Calling herself a grenade, Hazel realizes how dangerous she is for others when it explodes. She has an incurable illness and believes that she can die anytime and anywhere. She, therefore, avoids people at all times and tries not to be too close emotionally to anyone of them. In addition, in Hazel's case, there are two reasons as to why she fears intimacy. The first reason is that she is afraid she might get hurt when someone leaves her. The second thing she fears about is the possibility that people might get hurt if she explodes, i.e. dies and leaves them.

\section{Fear of Abandonment}

According to Tyson (2006), fear of abandonment is the unshakable belief that our friends and loved ones are going to desert us (physical abandonment) or do not really care about us (emotional abandonment). In The Fault in Our Stars, Hazel is constantly and acutely inflicted by this kind of fear. She is "haunted" by the thought that when she dies she abandons her parents and Augustus, his boyfriend.

Just before the miracle, when I was in the ICU and it looked like I was going to die and Mom was telling me it was okay to let go, and I was trying to let go but my lungs kept searching for air, Mom sobbed something into Dad's chest that I wish I hadn't heard, and that I hope she never finds out that I did hear. She said, "I won't be a mom anymore." It gutted me pretty badly. I couldn't stop thinking about that during the whole Cancer Team Meeting. I couldn't get it out of my head, how she sounded when she said that, like she would never be okay again, which probably she wouldn't (Green, 2013: 116117).

The citation above is an example which suggests that Hazel is afraid that her mother will not become her mother anymore after she dies. When Hazel abandons them, i.e. when she dies, her mother and father will never be fine. They will just sit around the house all day, staring at the walls. Hazel's intense fear of abandonment is also expressed in her dreams. One day, for example, she dreams of being alone in a huge lake. Through this dream, we know that Hazel is afraid of being abandoned and being alone.

I woke up the next morning panicked because I'd dreamed of being alone and boatless in a huge lake. I bolted up, straining against the BiPAP, and felt mom's arm on me (Green, 2013: 301).

From two textual evidences above, we can conclude that Hazel has constant fear of abandonment. She is both afraid of abandoning people around her and of being abandoned by people around her.

\section{Low Self-esteem}

Low self-esteem is the belief that we are less worthy than other people and, therefore, do not deserve attention, love, or any other of life's rewards (Tyson 2006). Hazel often feels herself as less worthy than others. This feeling is much more intensified after her being diagnosed with an incurable cancer. This causes her to think of herself as a nonregular teenager. She is different from others, but not only different because she feels as less worthy than others.

[T]here's nothing I can do about hurting you; you're too invested, so just please let me do that, okay? I'm not depressed. I don't need to get out anymore. And I can't be a regular teenager, because I'm a grenade (Green 2013: 99)

Just like most teenagers, Hazel often feels unconfident with herself. This feeling has characterized her form since who-knowswhen. But, as a child with cancer who is different and often looked at with pity by others, she has a more acute realization about her crippling situation. She sees herself as someone of less value than other, normal teenagers. As such she thinks she does not entitled with rights to love and be loved. We can see here that Hazel's fear of intimacy, fear of abandonment and low self-esteem entangle and enforce each other. 
Having elaborating Hazel's core issues in detailed, we now come to the big question: what causes those core issues. To answer this question, it is required that we carefully look into Hazel's childhood, particularly from the periods before she reaches the age of twelve, and finds patterns of experiences that build up into her core issues.

And yet as we can infer from the previous discussion, the novel The Fault in Our Stars does not say anything about the early period of Hazel's life. There is no significant information we can read from the chapters of the novel about how Hazel has spent the first twelve years of her life. The first bad childhood experience that was told of Hazel, as also been mentioned earlier, is when she is diagnosed with Stage IV thyroid cancer. Upon knowing that the cancer is incurable, she feels depressed. But, not a single pattern of traumatic experience that can be inferred or traced from Hazel's early childhood to lead us to the cause of her core issues. Since the novel does not present any bad childhood experiences when Hazel was in the range of age one until twelve years old, the cause of her core issues cannot be found in the novel.

\section{Conclusion}

John Green's The Fault in Our Stars has presented to us an interesting case of the main character that can be analyzed using Freudian psychoanalysis perspective. Analyzing a literary character using psychoanalysis is made possible because literary characters represent real human life. Understood this way, literary characters act as imitations of reality. In this discussion, we analyze Hazel's self-defense mechanisms and core issues. We also answer the questions: what causes those self-defense mechanisms and core issues by analyzing the textual evidence from the novel related to Hazel's childhood.

The finding of this research is that Hazel employs several self-defense mechanisms to defend herself in the face of threats. The mechanisms include selective perception, denial, avoidance, displacement, projection, fixation, identification and rationalization.
The research also finds Hazel's core issues, i.e. fear of intimacy, fear of abandonment, and low self-esteem.

Finding the answers to the question what is the cause Hazel's self-defense mechanisms and core issues is much more complicated and problematic. While we can vest a little confidence in the answer that it was Hazel's most traumatic experience, i.e. when she overhears her mother's terrified remark about her death, that triggers her to employ the self-defense mechanisms found in this research, we cannot even figure out what possibly cause her core issues. It is due to the fact that our text, the novel The Fault in Our Stars, does not even mention anything related to Hazel's early childhood. The story of Hazel as told by the author starts from when she was thirteenth. Prior to that, it is simply mentioned that Hazel has a happy, normal childhood.

There is no clear indication as to why John Green as the author does not bother to even mention or refer to his main character's childhood, except by saying that she has a happy childhood. But whatever the motives are, it makes the novel an example of an incomplete psychological novel. Bestselling it might be, it does not portray or represents human's life in its fullness.

\section{References}

Baek, S. Defense Mechanism, Seoul: Korea University Moosang's Right, 2011.

Berger, Peter. Psychoanalytic Criticism, London: Sage Publication, 2004.

Defense Mechanisms. n.d. Web. 22 October 2015, <www.coldbacon.com/ defenses.html>

Eagleton, Terry. Literary Theory: An Introduction, 2nd ed., Oxford: Blackwell, 1996. 
Endraswara, S. Metodologi Penelitian Sastra. Yogyakarta: CAPS, 2011.

Freud, Sigmund. The complete introductory lectures on psychoanalysis, trans. James Strachey. New York: W. W. Norton. 1966.

Freud, Sigmund. "The origin and development of psychoanalysis' The American Journal of Psychology, vol. 21, no. 2, pp. 181-218. 7 December 2014. Web. $<$ www.jstor.org/table/1413001>.

Green, John. The Fault in Our Stars. London: Penguin Books, 2011.

How not to recognize the truth: Ego-defense mechanisms n.d., Web. 22 October 2015, $<$ www.psychance.com/ego-defensemechanisms1.php>.

Kathy, P. Psychoanalysis: The defenses, anxiety and core issues, Educational Website Content Management. 17 November 2015. Web. <www.11th-grade-ibenglish.granadahills. groupfusion.net/ /modules/locker/

files/get_group_file.phtml?gid $=3937650$ \&fid=27609903>

Kazlev, A. Freud's view of the human mind: The mental iceberg, 22 October 2015. Web.

$<$ www.wilderdom.com/personality/L83Topograp hyMindIceberg.html>.

Kim, C. Defense Mechanism of Freud, Kentucky: Paintsville Independent Schools, 2011.

Literary conflict n.d., Web. 12 April 2015, $<$ www.cityschools.com/cpoud rier/files/2012/09/Literary-Conflictnotes.pdf $>$.

Novel n.d., Web. 6 December 2014, $<$ www.essayform.pbworks.com/f/WC54 -Novel.pdf $>$.

Nurgiyantoro, B. Teori Pengkajian Fiksi, Yogyakarta: Gadjah Mada University Press, 1995.
Nurgiyantoro, B (ed.). Teori Pengkajian Fiksi, Yogyakarta: Gadjah Mada University Press, 2009.

Oxford advanced learner's dictionary, 8th ed, Oxford: Oxford University Press, 2010.

Rivkin, J \& Ryan, M .Literary Theory: An anthology, $2^{\text {nd }}$ ed. Oxford: Blackwell, 2004.

Tyson, Loius. 2006, Critical Theory Today. New York: Routledge Taylor \& Francis Group, 2006.

Wellek, R, Warren, A, Literary theory, trans. M Budianta. Jakarta: Gramedia, 1989. 